\title{
PENGEMBANGAN TEKNOLOGI INFORMASI MOBILE LEARNING FAKULTAS TEKNIK UNIVERSITAS DIPONEGORO BERBASIS ANDROID
}

Resi Jiwa Kasatria (21120110120045)

Jurusan Teknik Sistem Komputer Fakultas Teknik Universitas Diponegoro

\begin{abstract}
Abstrak - Perkembangan teknologi mobile seluler sudah sedemikian cepat dan dapat dirasakan di seluruh dunia dan dimanfaatkan dalam berbagai bidang kehidupan. Perkembangan ini dapat pula dilakukan dalam dunia pendidikan dan memungkinkan terobosan baru dalam belajar secara mobile menggunakan perangkat teknologi informasi (handphone) atau disebut mobile learning (m-learning). M-learning memiliki beberapa kelebihan di antaranya adalah independensi dalam pembelajaran. Namun, di sisi lain, perangkat pembelajaran m-learning memiliki keterbatasan sumber daya dan keragaman platform sehingga diperlukan rancangan yang mampu menjamin kompatibilitas.

Aplikasi Mobile Learning ini dikembangkan menggunakan Java EE untuk menangani servernya dan untuk sisi klien menggunakan Bootstrap mobile. Basis data yang digunakan adalah MySQL. Aplikasi ini akan mempunyai 3 role pengguna yaitu admin yang akan menangani penambahan user dan pengelolaan mata kuliah, dosen yang akan memberikan materi, tugas dan kuis dan mahasiswa yang dapat melihat materi, tugas dan kuis yang diberikan dosen.

Mobile Learning ini dapat membantu dosen dan mahasiswa dalam melakukan interaksi dalam berbagi materi, dalam pemberian tugas dan mengerjakan kuis. Mahasiswa maupun dosen tidak lagi harus bertatap muka, yang diperlukan hanyalah koneksi internet untuk melakukan proses belajar mengajar. Selain itu Mobile Learning ini juga dapat berjalan dengan baik saat diuji pada 3 buah versi android yang berbeda yaitu versi 2.3 , versi 4.0 dan versi 4.2.
\end{abstract}

\section{Keywords: MySQL, Mobile Learning, Java EE, Bootstrap, Android}

\section{PENDAHULUAN}

Terkait antara peran TIK dalam dunia pendidikan, informasi pembelajaran yang disajikan dalam bentuk buku membuat seorang mahasiswa kurang tertarik, karena media pembelajaran yang ditampilkan oleh buku kurang tersedia secara lengkap sebagai media belajar karena yang ditampilkan hanya berupa teks dan pada tampilan isi buku yang tidak dapat divisualisasikan sehingga tampilannya monoton (tidak gerak, hitam putih). Hal ini dapat menyebabkan seorang mahasiswa akan cepat merasa jenuh dan minat belajar pun akhirnya dapat berkurang.

Salah satu cara yang tepat untuk mengatasi masalah tersebut adalah dengan mencari metode pembelajaran yang menarik dan interaktif. Pembelajan yang bersifat interaktif dan menarik, menambahkan visualisasi dengan animasi, teks, gambar-gambar, dan suara merupakan hal untuk membuat pembelajaran menjadi lebih menarik dan tidak monoton. Fakta menyatakan bahwa menyampaikan informasi dengan multimedia dapat meningkatkan ingatan dalam belajar karena materi dalam bentuk audio visual akan lebih mudah ditangkap dan secara fisiologis manusia akan lebih peka menggunakan inderanya. Dengan adanya aplikasi pembelajaran interaktif ini diharapkan akan dapat menambah minat belajar mahasiswa dan aplikasi ini pun dibuat sebagai media belajar mahasiswa menggunakan komputer karena keberadaan komputer saat ini telah banyak digunakan oleh masyarakat sebagai konsekuensi dari perkembangan dunia teknologi informasi.

Tugas akhir ini bertujuan untuk:

a. Membuat aplikasi yang dapat melengkapi proses belajar mengajar antara mahasiswa dan dosen yang masih konvensional.

b. Membuat aplikasi yang dapat membantu mahasiswa 
mendapatkan informasi maupun data yang paling baru dari dosen secara cepat.

c. Membuat aplikasi yang dapat membantu dosen dalam mengevaluasi mahasiswa dalam penerimaan materi yang telah diberikan oleh dosen dengan mudah.

d. Membuat aplikasi yang dapat meningkatkan mutu pembelajaran dalam dunia pendidikan berbasis mobile learning dimana dapat dijalankan dibeberapa versi android yang berbeda sesuai kebutuhan

Untuk menghindari pembahasan yang meluas, maka dalam tugas akhir ini ditetapkan batasan-batasan masalah sebagai berikut :

a. Tugas akhir ini hanya membahas mengenai pengembangan aplikasi pada sisi klien untuk dosen dan mahasiswa, sedangkan pada sisi server hanya untuk admin.

b. Aplikasi dijalankan pada sistem operasi Android.

c. Perancangan aplikasi pada sisi server menggunakan Java EE.

d. Perancangan aplikasi pada sisis klien menggunakan JQuery Mobile.

e. Basis data yang digunakan adalah MySQL.

f. Aplikasi ini hanya bersifat purwarupa dan dapat dikembangkan ke depannya.

g. Aplikasi ini hanya dikembangkan untuk lingkungan Fakultas Teknik Universitas Dipenogoro.

\section{DASAR TEORI}

\subsection{Teknologi Informasi}

Definisi dari teknologi Informasi dapat dibagi dalam beberapa bagian, antara lain:

- Rahardjo (2002), Teknologi Informasi adalah sama dengan teknologi lainnya, hanya informasi merupakan komoditas yang diolah dengan teknologi tersebut. Dalam hal ini, teknologi mengandung konotasi memiliki nilai ekonomi yang mempunyai nilai jual.

- Whitten (2004), Teknologi Informasi, adalah sebuah istilah yang menjelaskan kombinasi dari teknologi computer (hardware dan software) dengan teknologi telekomunikasi (data, gambar dan jaringan suara).

-Williams dan Swayer (2005), Teknologi Informasi adalah teknologi yang menggabungkan komputasi (komputer) dengan jalur komunikasi berkecepatan tinggi yang membawa data, suara dan video.

\subsection{Mobile Learning}

Mobile learning atau m-learning, telah di definisikan sebagai kegiatan belajar yang menggunakan perangkat bergerak seperti ponsel, PDA, atau laptop.

Pengembangan sistem mobile diarahkan pada dua sisi yaitu sebagai berikut:

a) Mengembangkan mobile server yang merupakan sebuah aplikasi layanan mobile berbasis web di sisi server.

b) Mengembangkan mobile client yang merupakan aplikasi mobile di sisi klien yang dapat mengakses layanan mobile server.

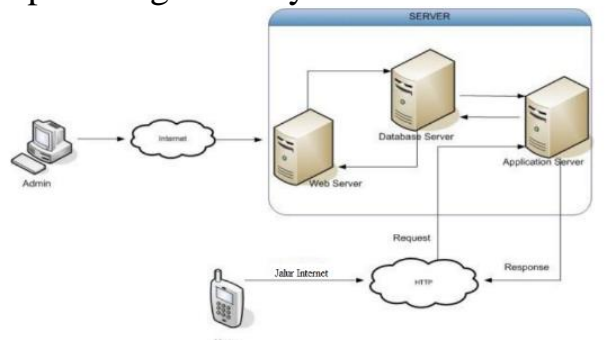

Gambar 2.1 Arsitektur aplikasi mobile

Dari Gambar 2.1 arsitektur sistem aplikasi mobile learning di atas dapat di lihat bahwa sistem yang dikembangkan dibagi menjadi 3 (tiga bagian) sebagai berikut:

a) Bagian admin yang berwenang untuk mengatur konten serta user dengan hak aksesnya.

b) Bagian server yang terdiri dari beberapa 3 (tiga) bagian:

- Basis data yang digunakan untuk menyimpan konten dari mobile learning

- Aplikasi berbasis web untuk mengatur (manajemen) konten mobile learning.

- Aplikasi server untuk menerima request dan memberi respon client.

c) Aplikasi client (aplikasi mobile learning) yang dikembangkan berbasis android yang akan berhadapan langsung dengan klien

\subsection{Bahasa Pemrograman}

Bahasa pemrograman merupakan bahasa yang digunakan dalam pembuatan perangkat lunak. Bahasa pemrograman tidak sama dengan bahasa alami atau bahasa yang 
dipakai sehari-hari. Pembuatan M-Learning ini menggunakan Java Enterprise Edition pada sisi server untuk admin, dan pada sisi klien menggunakan Bootstrap. Berikut merupakan bahasa pemrograman yang digunakan untuk membuat aplikasi Mobile Learning ini.

\subsubsection{Java EE}

J2EE adalah singkatan dari Java 2 Enterprise Edition, dan sejak versi 5 berubah menjadi Java EE atau Java Enterprise Edition. Java EE adalah sebuah spesifikasi, bukan berupa produk berwujud nyata. Ada banyak vendor perngkat lunak atau komunitas opensource membuat perangkat lunak berupa aplikasi server yang mengikuti standar Java EE sehingga disebut Java EE compliant application server (McGovern dkk, 2003).

\subsubsection{Framework Spring MVC}

Spring Framework adalah sebuah kerangka kerja opensource, yang diciptakan oleh Rod Johnson untuk masalah desain sistem dalam pengembangan aplikasi enterprise. Spring adalah solusi alternative Enterprise JavaBeans (Walls, 2011). Spring juga dapat mengimplementasikan beberapa teknologi IOC ke dalam sebuah proyek MVC (Model-View-Controler).

\subsubsection{Hibernate}

Hibernate dimulai pada tahun 2001 oleh Gavin King sebagai alternative penggunaan EJB2. Hibernate adalah sebuah pustakan pemetaan objek-relasisonal (Oject-relational mapping library) untuk bahasa pemrograman Java (Linwood and Minter, 2010).

Hibernate menyediakan framework untuk melakukan pemetaan dari model berbasis objek ke basis data relasional. Tujuannya adalah untuk menyederhanakan serta memberikan kemapuan persistence. Yang lebih baik dibandingkan EJB 2 yaitu dengan menyederhanakan kompleksitas seta menyempurnakan kekurangan fitur pada EJB2. Arsitektur dar Hibernate terdiri dari 3 komponen antara lain :

a. Manajemen Koneksi, menyediakan pengaturan efisien terhadapa koneksi basis data.

b. Manajemen Transaksi, menyediakan kemampuan kepada pengguna untuk mengeksekusi lebih dari satu perintah ke basis data dalam satu waktu.

c. Pemetaan objek-relasional, teknik untuk memetakan representasi data dari model objek ke model relasional .

Terdapat 3 bagian penting untuk melakukan proses pemetaaan basis data relasional ke model objek yaitu class java, berkas XML untuk pemetaan yaitu hibernate.xml dan berkas Hibernate.properties yang berisi pengaturan koneksi ke basis data.

Pada Gambar 2.3 di bawah ini menunjukkan hubungan antara aplikasi dengan basis data menggunakan hibernate. Proses pemetaan objek akan menggunakan persitance object dan diteruskan untuk dipetakan oleh hibernate.xml serta dihubungkan ke basis data menggunakan konfigurasi dari hibernate.properties .

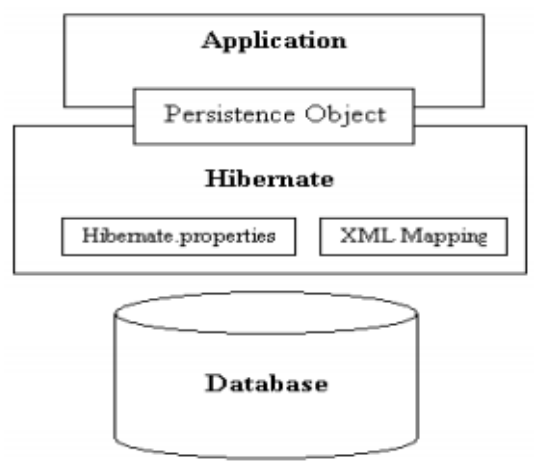

Gambar 2.3 Arsitektur Hibernate

\subsection{Pemrograman Berorientasi Objek}

Pemrograman berorientasi objek atau dalam bahasa inggris disebut dengan Object Oriented Programming (OOP) adalah suatu cara pemrograman yang mempunyai 2 komponen utama yaitu kelas dan objek (Wu C, 2010). OOP mencoba melihat permasalahan lewat pengamatan dunia nyata, dimana setiap objek adalah entitas tunggal yang memiliki kombinasi struktur data dan fungsi tertentu. Hal ini kontras dengan pemrograman terstruktur dimana struktur data dan fungsi didefinisikan secara terpisah dan tidak berhubungan secara erat.

\subsection{Sistem Operasi Android}

Menurut Nasruddin Safaat (2012), android adalah sebuah sistem operasi pada handphone yang bersifat terbuka dan berbasis pada sistem operasi Linux. Android di ambil alih oleh Google pada tahun 2005 dari Android, Inc sebagai bagian dari strategi untuk mengisi 
pasar sistem operasi bergerak. Google mengambil alih seluruh hasil kerja android termasuk tim yang mengembangkan android.

Google menginginkan agar android bersifat terbuka dan gratis, oleh karena itu hampir setiap kode program Android diluncurkan berdasarkan lisensi open source Apache yang berarti bahwa setiap orang yang ingin menggunakan Android dapat mendownload penuh source code nya.

Disamping itu produsen perangkat keras juga dapat menambahkan extension-nya sendiri ke dalam android sesuai kebutuhan produk mereka. Model pengembangan nya yang sederhana membuat Android menarik bagi vendor-vendor perangkat keras.

Keuntungan utama dari Anroid adalah adanya pendekatan aplikasi secara terpadu. Pengembangan hanya berkonsentrasi pada aplikasi, aplikasi tersebut dapat berjalan pada beberapa perangkat yang berbeda selama masih ditenagai oleh Android.

III. ANALISA dan PERANCANGAN

\subsection{Analisa Kebutuhan}

Beberapa kriteria yang diharapkan ada pada aplikasi M-Learning ini adalah sebagai berikut:

a. Admin dapat mengelola user yaitu dosen dan mahasiswa serta mengelola mata kuliah dan materi.

b. Dosen dapat mengunggah materi dan mahasiswa dapat mengunduh materi yang telah diunggah dosen dimanapun dan kapanpun melalui Smartphone android.

c. Dosen dapat memberikan tugas melalui smartphone android sehingga mahasiswa dapat melihat tugas yang telah diberikan dosen dengan lebih mudah melalui android nya.

d. Dosen dapat memberikan kuis dan dapat melihat evaluasi hasil kuis tersebut yang telah dikerjakan mahasiswa secara otomatis, karena sudah di koreksi secara otomatis oleh sistem.

e. Mahasiswa dapat melihat nilai yang dipeperanh dari pengerjaan kuis yang telah diberikan oleh dosen.

Dari kriteria yang telah dipaparkan maka akan disimpulkan beberapa kebutuhan yang dibutuhkan oleh sistem adalah sebagai berikut:

\section{Kebutuhan Fungsional}

Kebutuhan fungsional merupakan kebutuhan yang meliputi fungsi yang ada pada aplikasi dan berkaitan langsung dengan fitur fitur pada aplikasi. Kebutuhan Fungsional dari aplikasi M-Learning ini adalah sebagai berikut:

a. Akan dibagi 3 macam peran untuk user yaitu:

- Administrator

- Dosen

- Mahasiswa

b. Fasilitas admin dapat mengelola user dan mata kuliah.

c. Fasilitas dosen mengunggah materi melalui perangkat bergerak.

d. Fasilitas dosen menambah tugas melalui perangkat bergerak.

e. Fasilitas dosen memberikan kuis melalui perangkat bergerak.

f. Fasilitas mahasiswa mengunduh materi, melihat tugas dan mengerjakan kuis yang diberikan dosen melalui perangkat bergerak.

g. Dosen dan Mahasiswa dapat langsung melihat hasil pengerjaan kuis setelah dikerjakan.

\section{Kebutuhan non Fungsional}

Kebutuhan non fungsional tidak berkaitan langsung dengan fitur-fitur pada aplikasi namun kebutuhan ini akan memberikan batasan kepada kebutuhan fungsional. Berikut merupakan kebutuhan non fungsional aplikasi M-Learning.

a. Operasional

Dapat diakses melalui smartphone android.

b. Keamanan

Adanya penggunaan username dan password untuk bisa masuk ke dalam aplikasi M-Learning dan adanya pembagian hak akses untuk tipe peran yang diberikan kepada tiap user.

\subsection{Diagram Alir}

Diagram alir penelitian ditunjukkan oleh Gambar 3.1. 

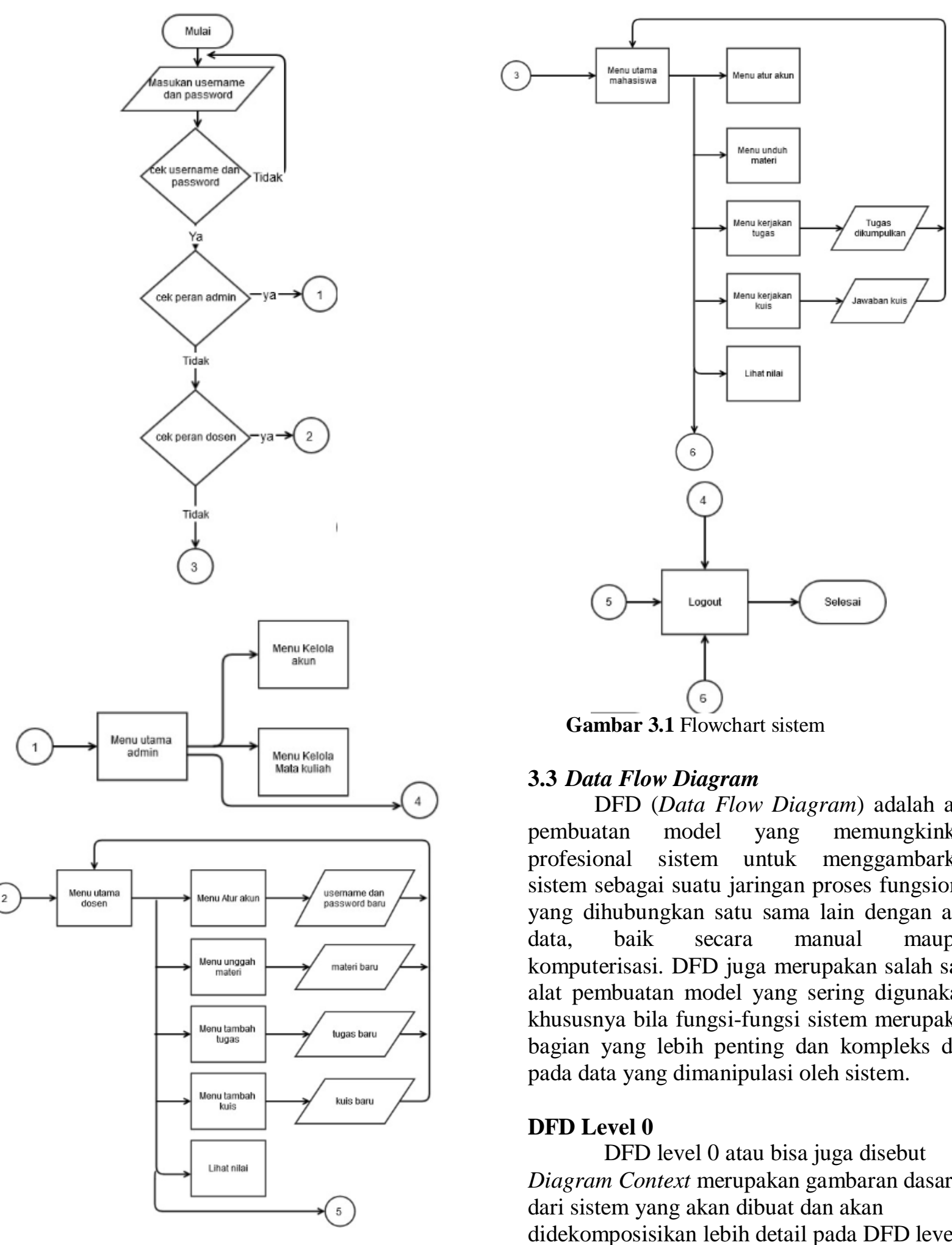

Gambar 3.1 Flowchart sistem

\subsection{Data Flow Diagram}

DFD (Data Flow Diagram) adalah alat pembuatan model yang memungkinkan profesional sistem untuk menggambarkan sistem sebagai suatu jaringan proses fungsional yang dihubungkan satu sama lain dengan alur data, baik secara manual maupun komputerisasi. DFD juga merupakan salah satu alat pembuatan model yang sering digunakan, khususnya bila fungsi-fungsi sistem merupakan bagian yang lebih penting dan kompleks dari pada data yang dimanipulasi oleh sistem.

\section{DFD Level 0}

DFD level 0 atau bisa juga disebut Diagram Context merupakan gambaran dasar dari sistem yang akan dibuat dan akan didekomposisikan lebih detail pada DFD level selanjutnya. Gambar 3.2 akan menjelaskan aliran data pada DF level 0. 


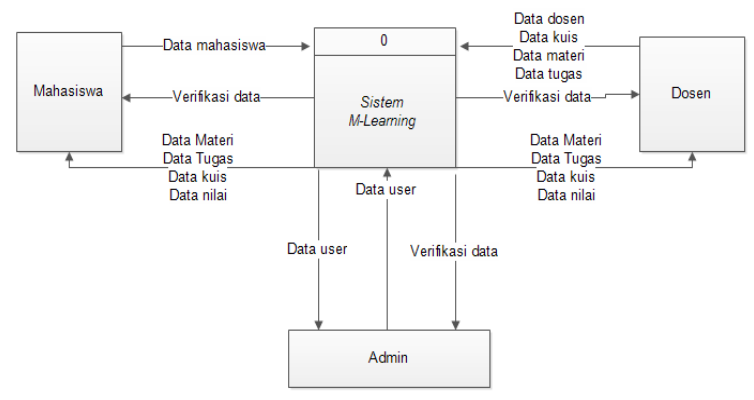

Gambar 3.2 Diagram Context

\section{DFD Level 1}

Pada DFD level 1 ini sistem $M$ Learning akan terdapat 5 buah proses seperti terlihat pada Gambar 3.3, yaitu :

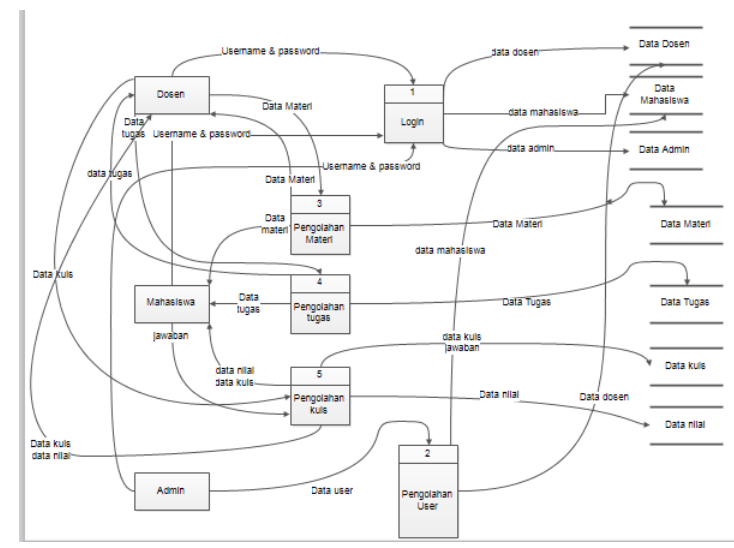

Gambar 3.3 DFD Level 1

\section{PEMBAHASAN}

\subsection{Implementasi Perangkat Keras dan Perangkat Lunak}

Spesifikasi perangkat keras yang digunakan dalam membangun aplikasi $M$ Learning ini adalah sebagai berikut :

a. Notebook Intel ${ }^{\circledR}$ Core $^{\mathrm{TM}}$ i3-2310M dengan kecepatan $2.10 \mathrm{GHz}$

b. Memori (RAM) 4 GB

c. Harddisk $500 \mathrm{~GB}$

d. Monitor resolusi 1280 x 800 pixel Sedangkan perangkat lunak yang digunakan adalah sebagai berikut:

a. Sistem Operasi Windows 8

b. Apache Tomcat 7

c. PHP MyAdmin

d. Eclipse IDE for Java EE Developers

e. Android Development Tools

f. Browser : Mozilla Firefox dan Google Chrome.

\subsection{Pengujian Sistem}

\section{Login}

Untuk fungsi login dapat dilihat pada gambar 4.1 berikut:

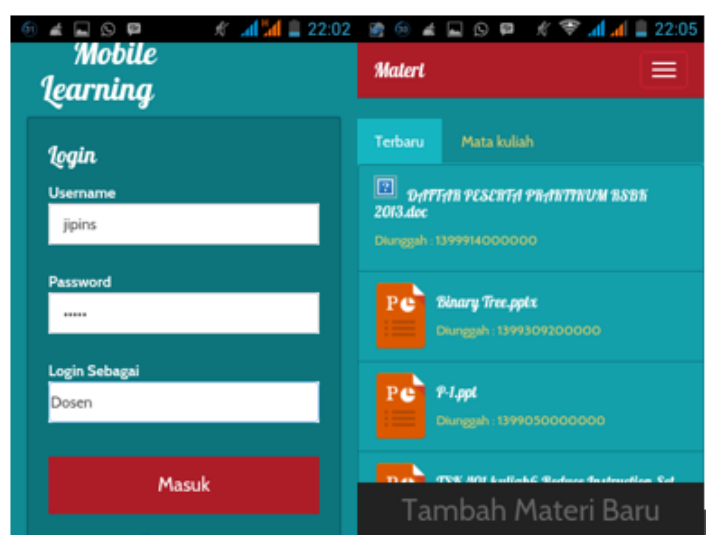

Gambar 4.1 Login sebagai dosen

\section{Pengelolaan User}

Untuk fungsi pengelolaan pengguna dapat dilihat pada gambar 4.2 dan Gambar 4.3 berikut:
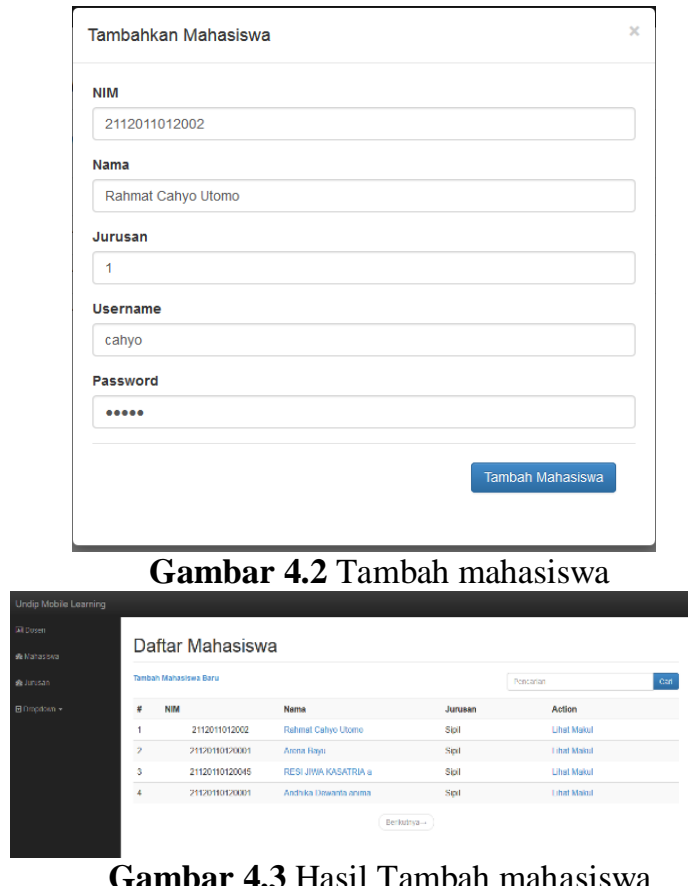

\section{Pengelolaan Jadwal dan Dokumen}

Untuk fungsi pengelolaan jadwal dan dokumen dapat dilihat pada gambar 4.4 dan Gambar 4.5 berikut

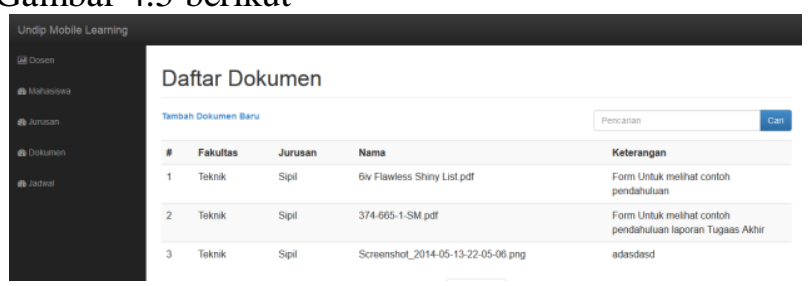


Gambar 4.4 Tambah Dokumen dan Jadwal

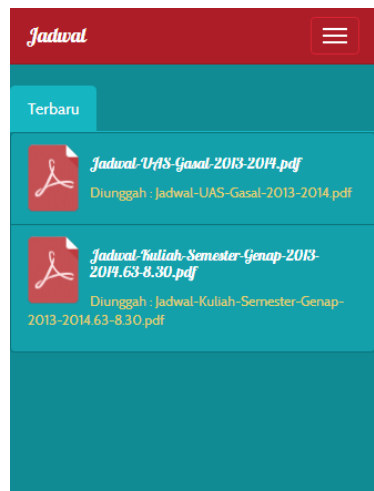

Gambar 4.5 Pengelolaan lihat Dokumen dan Jadwal

\section{Pengelolaan Materi}

Untuk fungsi pengelolaan materi dapat dilihat pada gambar 4.6 dan Gambar 4.7 berikut:

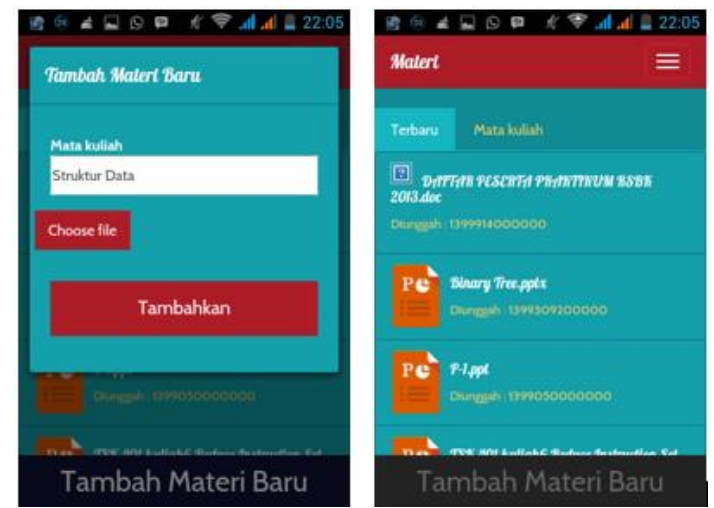

Gambar 4.6 Pengelolaan materi

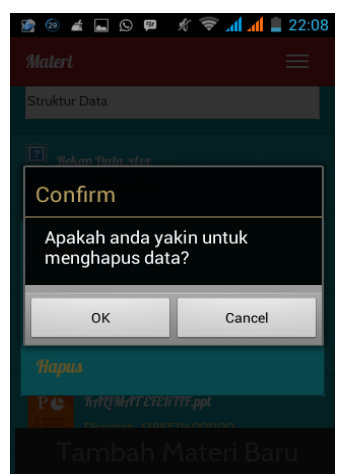

Gambar 4.7 Pengelolaan hapus materi

\section{Pengelolaan Tugas}

Untuk fungsi pengelolaan tugas dapat dilihat pada gambar 4.8 dan Gambar 4.9 berikut:

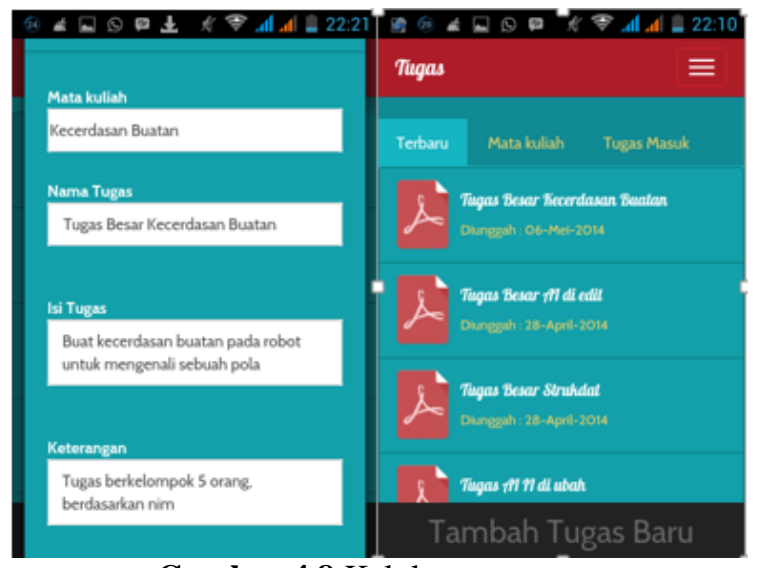

Gambar 4.8 Kelola tugas

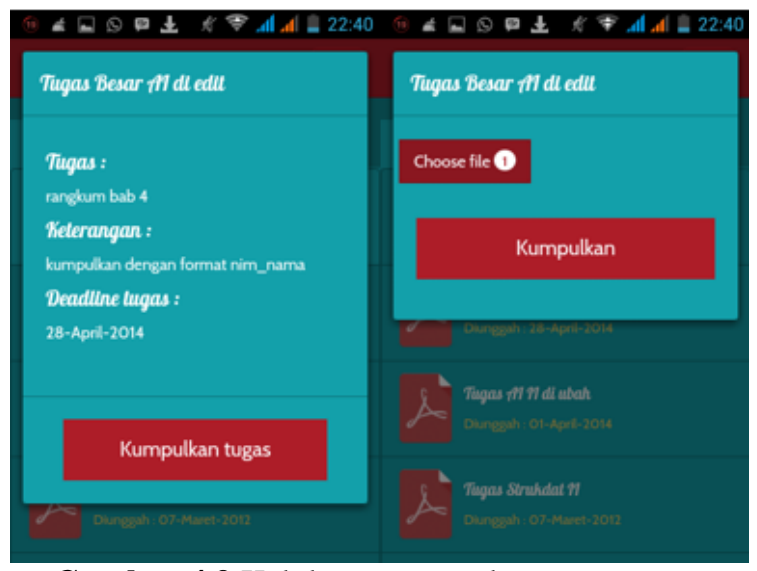

Gambar 4.9 Kelola pengumpulan tugas

\section{Pengelolaan Nilai}

Untuk fungsi pengelolaan nilai dapat dilihat pada gambar 4.10 berikut:

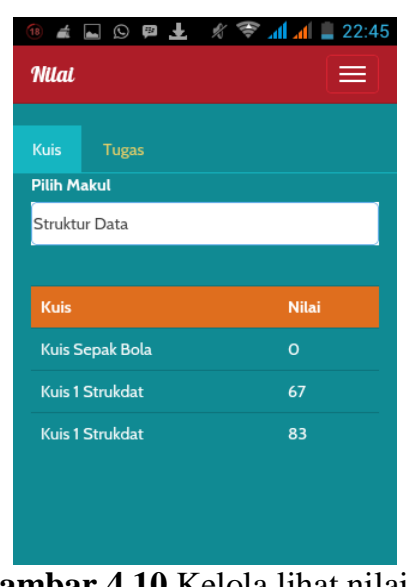

\section{Pengelolaan Kuis}

Untuk fungsi pengelolaan kuis dapat dilihat pada gambar 4.11 dan Gambar 4.12 berikut: 


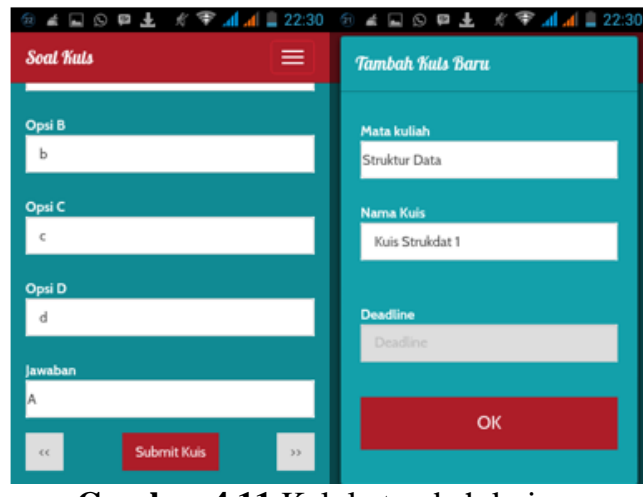

Gambar 4.11 Kelola tambah kuis

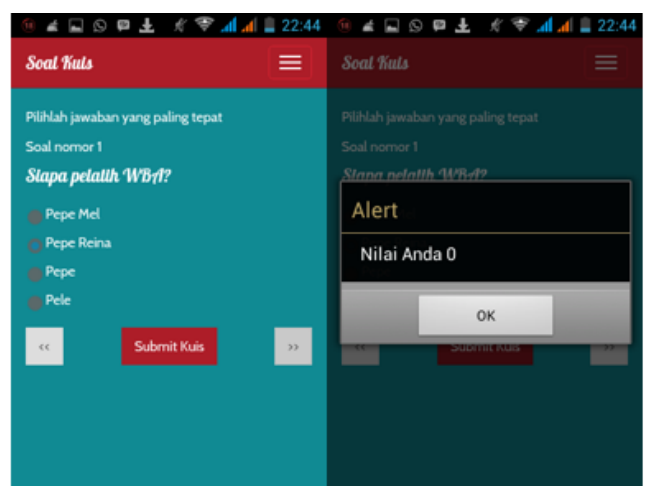

Gambar 4.12 Kelola kerjakan kuis

\section{PENUTUP}

\subsection{Kesimpulan}

1. Mobile Learning ini dapat melengkapi sistem belajar mengajar antara dosen dan mahasiswa fakultas teknik universitas diponegoro yang sekarang ini dilakukan secara konvensional menjadi lebih cepat dan mudah .

2. Dengan aplikasi Mobile Learning ini pemberian data materi, tugas maupun kuis dari dosen dapat diberikan secara cepat dan dapat di-update sehingga data yang diterima mahasiswa adalah yang terbaru.

3. Aplikasi Mobile Learning dapat membantu dosen dalam proses evaluasi belajar mahasiswa dengan adanya fitur mengerjakan kuis dan pemberian nilai secara langsung yang diatur oleh proses bisnis aplikasi.

4. Berdasarkan pengujian terhadap beberapa versi android, maka dapat disimpulkan bahwa aplikasi M-Leaning dapat berjalan pada versi android 2.3 (Froyo), versi android 4.0 (ICS) dan versi android 4.2 (Jelly Bean)

\subsection{Saran}

1. Perlu dilakukan penelitian lebih lanjut mengenai M-Learning ini agar dapat diterapkan di platform lain seperti Blackberry dan IOS.

2. Perlu adanya penelitian lebih lanjut mengenai M-Learning agar dapat sepenuhny diintegrasikan dengan SIA Universitas Diponegoro.

3. Perlu adanya penelitian lebih lanjut untuk penambahan fitur - fitur baru untuk M-Learning dimana pengguna akan mendapatkan notifikasi saat ada data baru yang dimasukkan oleh dosen

\section{DAFTAR PUSTAKA}

Brian K, W., \& Sawyes, S. C. (2005). Using Information Technology Practical Introduction to Computers \& Communications. Newyork, USA: McGraw Hill.

Linwood, J., \& Monter, D. (2010). Beginning Hibernate, Second Edition. New York: Springer-Verlag.

McGovern, J., Adatia, R., Fain, Y., Gordon, J., Henry, E., Hurst, W., . . Phillips, L. A. (2003). Java ${ }^{\mathrm{TM}} 2$ Enterprise Edition 1.4 Bible. Canada: Wiley Publishing, Inc.

Rahardjo, B. (2002). Memahami Teknologi Informasi. Jakarta: Elex Media Komputindo.

Safaat, N. (2012). Pemrograman Aplikasi Mobile Smartphone dan Tablet PC Berbasis Android. Bandung: Informatika.

Walls, C. (2011). Spring in Action THIRD EDITION. New York: Manning Publications Co.

Whitten, J. L., Bentley, L. D., \& Dittman, K. (2004). System Analysis and Design (6th ed.). Irwin: McGraw Hill Companies.

Wu, C. Thomas,2010..An introduction to object-oriented programming with Java. New York, USA. 